\title{
Mycorrhizal Association in Quinoa (Chenopodium quinoa Willd.) increase Phosphate Uptake under Water Stress Condition
}

\author{
Prashanthisandepogu* and M. Mamatha \\ DL in Botany, TSWRDC (W), Mahendrahills, Hyderabad, India \\ Department of Basic and social sciences, FCRI, Mulugu at Hyderabad, India \\ *Corresponding author
}

Keywords

VA Mycorrhizal fungus, Glomus fasciculatum, Quinoa, N, P, Moisture, External mycelium

Article Info

Accepted:

20 March 2021

Available Online:

10 April 2021

\section{A B S T R A C T}

The influence of soil moisture on the infection, hyphal development and uptake of P of a VA mycorrhizal fungus Glomus fasciculatum in Quinoa was studied at four different moisture levels $(-0.2 ;-0.6 ;-1.2$ and $-2.4 \mathrm{MPa})$. Maximum increase in dry weight was observed at $-0.2 \mathrm{MPa}$ level. There was a proportionate increase in total $\mathrm{P}$ content in shoot and root of a plant at decreased moisture levels. However, total $\mathrm{N}$ content increased only in roots, but not the shoots. The inflection, spore number and hyphal density were highest at low moisture level $(-2.4 \mathrm{MPa})$ because of ramifying external mycelium in the soil.

\section{Introduction}

Vesicular arbuscular mycorrhizal fungi can adapt to a wide range of soil water regimes and can be found in extreme habitats $1 \mathrm{R}$. In arid regions the low level of soil moisture will reduce the phosphate diffusion 2 R.In such conditions VA mycorrhizal fungi improve the phosphate nutrition of the plant by increasing the absorbing area for water uptake through ramifying hypae into the soil. Several authors have reported the soil moisture levels and mycorrhizal association in many plants 3R; 4RResistance to water transport in mycorrhizal wheat 5R. onion $6 \mathrm{R}$. and black walnut (7R) have been also reported. In this paper we report the influence of soil moisture levels on mycorrhizal association in Quinoa.

\section{Materials and Methods}

The experiment soil was a phosphorus deficient black sandy loam soil ( $\mathrm{pH}$ 7.2) containing $4 \mathrm{mg} / \mathrm{kg}$. NaHCo3 soluble P (Olsen et al., 1954). Earthen pots with $5 \mathrm{~kg}$ of soil were sterilized for one hour and stored at room temperature for one week. Glomus fasciculatum (Thaxter sensu Gerd.) Gerd. And Trappe, maintained in Panicum maximum Jacq. In pot culture was used as inoculum. 50 
$\mathrm{ml}$ of inoculum containing spores (325) and infected roots $(85 \%)$ was uniformly distributed below $2 \mathrm{~cm}$ in all mycorrhizal pots. For control treatment the sieved soil suspension was added to maintain the rhizosphere of soil. Three Quinoa plants were grown per pot. Seedlings emerged after one week and the following watering cycle was performed.

They were:

Watered every day (-0.2 MPa);

Watered every second day (0.6 MPa);

Watered every third day (-1.2 MPa)

Watered every fourth day (-2.4 MPa).

The above mentioned matric potentials were approximately equivalent to soil moisture levels. It was measured by using the instrument 'wescor' is a thermocouple Psychrometer $(1 \mathrm{MPa}=10$ bars $)$. The plants were maintained in greenhouse condition and in respective soil moisture levels. Hoagland (P) solution was added once a week. The plants were harvested after every 25 days up to 75 days. Three replicates were maintained for each treatment.

Dry weight of shoots and roots was recorded after drying at 80 degrees Celsius for one day. Total $\mathrm{N}$ and $\mathrm{P}$ content of the plants were analysed by Microkjeldhal method (Bremner, 1960) and molybdenum blue method (Allen, 1940) respectively. The percentage of colonization was calculated after clearing the roots with $\mathrm{KOH}$ and staining with Trypan blue (Phillips and Hayman, 1970). Spore content in $50 \mathrm{ml}$ of soil was determined by wet sieving and decanting (Gerdemann and Nicolson, 1963). The hyphal density was measured by binocular micrometer (Bethlenfalvay and Ames, 1986).

\section{Results and Discussion}

The influence of Glomus fasciculatum on Quinoa at four different moisture levels was studied. The influence of soil water levels on the dry weight, total $\mathrm{P}$ and $\mathrm{N}$ of mycorrhizal plants is given in table 1. There was a significant difference observed in all the parameters at 90 days but the differences were not significant at 25 and 50 days (data not shown). The plants watered every day showed the maximum increase over the control with respect to dry weight of shoot and root $(75.5 \%$ and $68.8 \%$ respectively). The plants which were watered every second day or third day or fourth day showed proportionate decrease in dry weight of the shoot over the control. However there was proportionate increase with total P content in shoot and root (92.7, 97.4, 108.6, and 129.0. 131.3, 142.9, 146.2, and 154.0 respectively). The increase in total $\mathrm{N}$ content in the mycorrhizal plants with respect to the control was altered at different moisture levels in roots but not in shoots. The percentage infection and hyphal density are given in figure 1 and 2 . The infection and hyphal density in soil were increased about 25 to 30 percent in the plants maintained with lowest moisture level (-2.4 MPa). However, the spore content was increased only $10 \%$ in lowest moisture levels (figure 3 ). These results suggest that at the altered soil moisture levels the degree of infection and extra radical mycelium are altered to meet the water requirement of the plant.

VAM - infected plants are less susceptible to wilting and transplant shock in low level of soil moisture (levy and krikvn, 1980). In the water stress condition VAM - infected plant has the ability to absorb the nutrients with the development of external mycelium. Allen and Boosalis (1983) found reduction in the resistance to water transport in stressed mycorrhizal wheat plant at high $\mathrm{P}$ nutritional regime. 
Table.1 Influence of Glomus fasciculatum on the dry weight, total P and total N of Quinoa at four different moisture levels.

\begin{tabular}{|c|c|c|c|c|c|c|c|}
\hline \multirow{2}{*}{ Water cycle } & \multirow{2}{*}{ Treatment } & \multicolumn{2}{|c|}{ Dry weight } & \multicolumn{2}{c|}{$\begin{array}{c}\text { Total P } \\
\text { mg/plant }\end{array}$} & \multicolumn{2}{c|}{$\begin{array}{c}\text { Total N } \\
\text { Mg/plant }\end{array}$} \\
\cline { 3 - 7 } & & Shoot & Root & Shoot & Root & Shoot & Root \\
\hline Every day (-0.2 & NM & 4.5 & 1.6 & 4.1 & 1.6 & 51.3 & 22.8 \\
KPa) & M & 7.9 & 2.7 & 7.9 & 3.7 & 78.9 & 32.1 \\
\hline Second day (- & NM & 3.7 & 1.3 & 3.8 & 1.7 & 50.7 & 21.7 \\
0.6 MPa) & M & 6.3 & 2.1 & 7.5 & 3.4 & 77.2 & 30.8 \\
\hline Third day (-1.2 & NM & 2.6 & 0.8 & 3.5 & 1.3 & 48.2 & 19.5 \\
MPa) & M & 4.2 & 1.2 & 7.3 & 3.2 & 74.1 & 29.1 \\
\hline Fourth day (-2.4 & NM & 1.5 & 0.8 & 3.1 & 1.1 & 43.3 & 17.6 \\
MPa) & M & 2.3 & 1.3 & 7.1 & 2.8 & 66.5 & 26.8 \\
\hline Mean & NM & 3.1 & 1.1 & 3.6 & 1.4 & 48.4 & 20.4 \\
& M & 5.2 & 1.8 & 7.5 & 3.3 & 74.2 & 29.7 \\
\hline Mean difference & & 1.1 & 0.7 & 3.9 & 1.9 & 25.8 & 9.3 \\
\hline LSD (P= 0.05) & & 1.0 & 0.6 & 1.8 & 0.8 & 5.7 & 2.9 \\
\hline LSD (P=0.01) & & 1.4 & 0.7 & 2.5 & 1.1 & 8.5 & 4.1 \\
\hline
\end{tabular}

NM - Non mycorrhiza

M - Mycorrhiza

LSD - Least significant difference

This reduced resistance in mycorrhizal plant could have resulted from improved water uptake, increased photosynthesis or elevated cytokinin levels which stimulate stomatal opening. However mycorrhizal plants may also have a great tolerance for continued drought. Our results suggest the increase in the dry weight mycorrhizal plant in daily watered condition. VAM fungi are known to increase $\mathrm{P}$ uptake in the host plant which in turn is known to stimulate nitrogen uptake (8R). We observed a significant increase in the $\mathrm{P}$ content of Quinoa at high stress condition inoculated with Glomus fasciculatum.

It is likely that mycorrhizal infection can alter membrane permeability through improved nutrition or increased production of photosterols, thereby influencing water transport. Besides, there was an increase in the amount of $\mathrm{N}$ in roots than shoots with respect to control plants. Ponder (1983) found that mycorrhizal fungi by passing the dry zones and $\mathrm{P}$ depletion zones through the extended root system by external fungal Hypae in black walnut. Similarly here also there was an increase in the intensity of VAM colonization spore number and Hyphal density in high water stress condition (-2.4MPa). However, the high soil moisture level was not favourable for fungal colonization because of water logging and oxygen deficiency. Obviously Pea plants benefits from mycorrhizal fungi at low level of $\mathrm{P}$ and water stress conditions. However, it is not clear, this effect is a direct result of fungal invasion and/or attributable to improved water flow through hyphae or a secondary response due to improved nutrition or physiological alternation of the host.

\section{References}

Vesicular Arbuscular Mycorrhizal (VAM) fungi- as a major biocontrol agent in modern sustainable agriculture system, March 2017, Russian Agricultural Sciences 43(2):138-143. 


\section{How to cite this article:}

Prashanthisandepogu and Mamatha, M. 2021. Mycorrhizal Association in Quinoa (Chenopodium quinoa Willd.) increase Phosphate Uptake under Water Stress Condition. Int.J.Curr.Microbiol.App.Sci. 10(04): 830-833. doi: https://doi.org/10.20546/ijcmas.2021.1004.086 